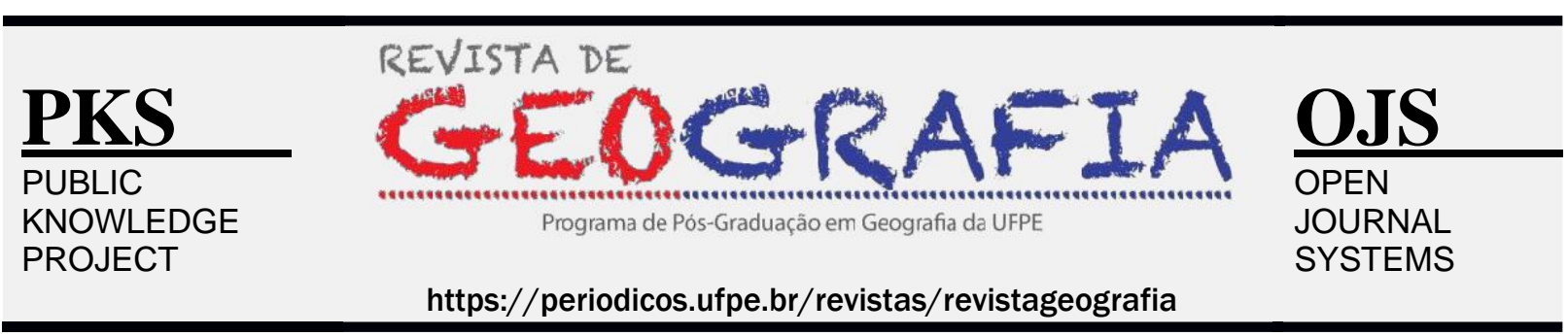

\title{
AS RELAÇÕES DO CIRCUITO SUPERIOR E DO CIRCUITO INFERIOR NO EIXO RODOVIÁRIO NATAL-CAICÓ, RIO GRANDE DO NORTE, BRASIL
}

\author{
Diego Salomão Candido de Oliveira Salvador ${ }^{1}$
}

${ }^{1}$ Doutor em Geografia pela UNICAMP, Professor do GEOCERES e do PPGe, UFRN, diegosalomao84@hotmail.com

Artigo recebido em 22/05/2018 e aceito em 23/11/2019

\begin{abstract}
RESUMO
Os circuitos da economia urbana não existem separadamente; eles coexistem, sendo subsistemas de um só sistema urbano: a cidade. A modernização econômica - geradora de uma economia superior, alicerçada na exploração do trabalho para a obtenção de altos lucros e de uma intensificação da situação de pobreza da maioria da população é a razão para a existência entrecruzada de um circuito hegemônico e um não hegemônico da economia urbana dos países subdesenvolvidos. Quanto mais essa modernização se adensa no território nacional, mais intensas e complexas se tornam as relações entre os circuitos. Neste artigo, compreendemos as relações entre os circuitos da economia urbana no eixo rodoviário Natal-Caicó (RN), atentando para a formação dos subsistemas da economia urbana, os usos da variável finanças e a rede de mercadorias estabelecida pelos circuitos. Assim, encerramos nossas reflexões e análises considerando que o circuito inferior é proeminente na economia urbana do eixo rodoviário Natal-Caicó, coexistindo com o circuito superior por relações de concorrência, complementaridade e subordinação. Palavras-chave: Circuitos da economia urbana; Coexistência; Eixo rodoviário Natal-Caicó.
\end{abstract}

\section{THE RELATIONSHIP OF THE UPPER AND LOWER CIRCUIT ON THE ROAD AXIS NATAL-CAICÓ, RIO GRANDE DO NORTE, BRAZIL}

\begin{abstract}
The circuits of the urban economy do not exist separately; they coexist, being subsystems of a single urban system: the city. The economic modernization - which generates a superior economy, based on exploration work for obtaining high profits and an intensification of the situation of poverty of the majority of the population - is the reason for the coexistence of a hegemonic circuit and a non-hegemonic of the urban economy of underdeveloped countries. The more this modernization increase in the national territory, more intense and complex become relations between the circuits. In this article, we understand the relationship between urban economy circuits on the road axis Natal-Caicó (RN), paying attention to the formation of the subsystems of the urban economy, the uses of the finances and the network of merchandises established by the circuits. Therefore, we closed our reflections and analyses whereas the lower circuit is prominent in urban economics from the road axis Natal-Caicó, coexisting with the circuit higher with competition, complementarity and subordination relations.
\end{abstract}

Keywords: Circuits of the urban economy. Coexistence. Road axis Natal-Caicó. 


\section{INTRODUÇÃO}

Os circuitos da economia urbana não existem separadamente; eles coexistem, sendo subsistemas de um só sistema urbano: a cidade. A modernização econômica - geradora de uma economia superior, alicerçada na exploração do trabalho para a obtenção de altos lucros e de uma intensificação da situação de pobreza da maioria da população urbana - é a razão para a existência entrecruzada de um circuito hegemônico e um não hegemônico da economia urbana dos países subdesenvolvidos (SANTOS, 1978a). Quanto mais essa modernização se adensa no território nacional, mais intensas e complexas se tornam as relações entre os circuitos.

Evidenciando que tais subsistemas devem ser analisados de modo relacional, Santos (1978b) atribui a cada um a denominação de "circuito", a qual alude às relações existentes entre eles e dentro de cada subsistema. Essas relações são de complementaridade, já que os dois circuitos, integrados, formam o sistema urbano, que é a cidade, mas também de concorrência, na qual o circuito superior comanda as variáveis-chave do período atual (técnica, informação, finanças, consumo) e a infraestrutura do referido sistema e, assim, subordina o circuito inferior. Desse modo, os circuitos existem em permanente estado de equilíbrio instável.

Para compreender as relações entre os circuitos da economia urbana no eixo rodoviário Natal-Caicó ${ }^{1}$ (figura 1), realizamos trabalho de campo em todas as cidades cortadas por rodovia, entre os meses de agosto de 2013 e janeiro de 2014. Aplicamos questionário com responsáveis por atividades não hegemônicas ${ }^{2}$ e realizamos registros fotográficos de aspectos concernentes às relações entre os circuitos e às características do circuito inferior. Ao todo, aplicamos 148 questionários, cujos dados nos possibilitam refletir sobre a natureza relacional dos circuitos, no que tange à formação dos subsistemas da economia urbana, aos usos da variável finanças e à rede de mercadorias estabelecida pelos circuitos.

\footnotetext{
${ }^{1}$ Dos eixos rodoviários do Rio Grande do Norte - Natal-Fronteira Paraibana, Natal-Mossoró, Natal-Caicó e Natal-Macau -, assinalamos o Natal-Caicó, devido ao fato dele interligar municípios do interior e do litoral do estado, se destacar pelos fluxos intermunicipais de passageiros e se caracterizar por cidades cujo centro econômico é a rodovia que as atravessa. Assim, neste trabalho, apreendemos a fluidez territorial e a dinâmica urbana do referido eixo rodoviário.

${ }^{2}$ A pesquisa de campo foi realizada com agentes não hegemônicos da economia urbana tendo em vista a proeminência do circuito inferior no eixo rodoviário Natal-Caicó. Dados quantitativos e qualitativos decorrentes de trabalhos de campo explicitam essa proeminência: quantitativamente, esse subsistema equivale a 70\% das atividades existentes no eixo; qualitativamente, tem importância na dinâmica do território, ao usar e banalizar variáveis do período atual, possibilitar ocupação e renda para a maioria dos trabalhadores e explicitar o território usado como fator de desigualdades, alternativas e resistências.
} 


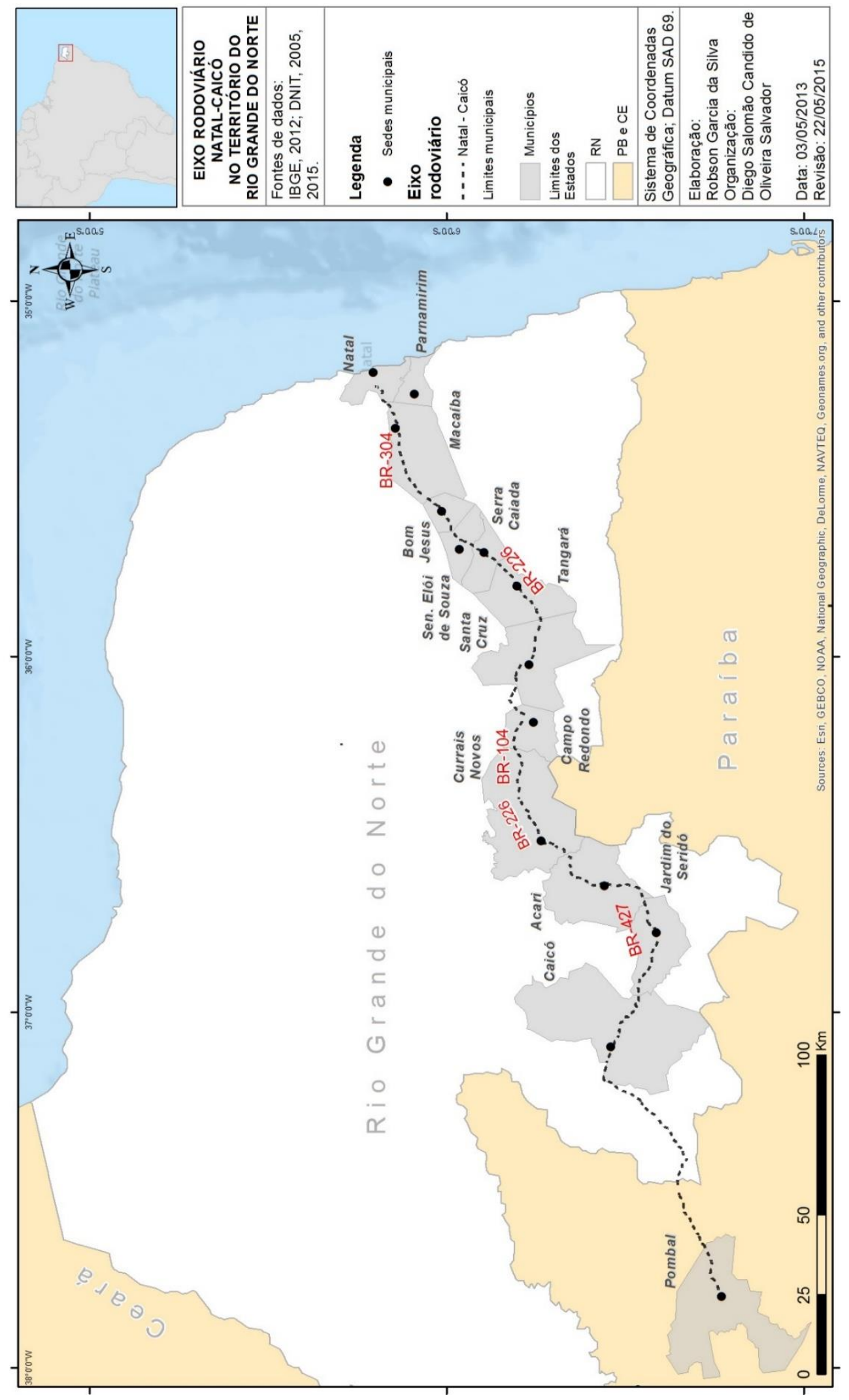

Figura 1 - Eixo rodoviário Natal-Caicó no território do Rio Grande do Norte Fonte: Organização do autor (2013). 


\section{A SEGMENTAÇÃO DA ECONOMIA URBANA}

A modernização econômica verticalizada no território dos países subdesenvolvidos é calcada na industrialização com importação de desenvolvimento tecnológico assim como no planejamento e ordenamento territorial privilegiando os anseios de agentes hegemônicos. Desse processo, decorre diretamente o subsistema superior da economia urbana, responsável pela exploração do território, considerado recurso (SANTOS, 1978a).

O referido processo de modernização também é fundamentado no desenvolvimento de um modelo industrial que tem como pilares a intensa produtividade, o alto rendimento obtido com a exploração do trabalho, a geração de poucos empregos e a propagação da ideologia do consumo exacerbado a qualquer custo. Disso decorre a precarização do trabalho, com a intensificação da situação de pobreza da maioria dos trabalhadores. Estes geralmente migram do campo para a cidade ou de uma cidade menor para uma maior demográfica e funcionalmente, em busca de emprego que lhes possibilite melhores condições de vida. Contudo comumente não são empregados pelo circuito superior, ou quando o são, logo se tornam desempregados, tendo, assim, que desenvolver alguma ocupação no circuito inferior que represente abrigo para sua sobrevivência e a de sua família.

É isso que vem ocorrendo com trabalhadores do eixo rodoviário Natal-Caicó. Aqueles que nasceram em uma cidade local $^{3}$ frequentemente migram para um centro regional sertanejo ${ }^{4}$ próximo ou para a capital estadual, visando a maiores e melhores oportunidades de trabalho. Na cidade escolhida para trabalhar, muitos se estabelecem e desenvolvem sua própria atividade, passando a integrar o circuito inferior da economia urbana. Também há trabalhadores que migram do campo para a cidade local e buscam seu sustento nesse espaço, sobretudo por meio de atividade não hegemônica.

Assim, para a maioria dos trabalhadores $(48,6 \%)$, a atividade do circuito inferior do eixo rodoviário Natal-Caicó é a maneira disponível para sobreviver e consumir, sendo praticada não por uma questão de escolha, mas pela falta de outra opção. Eles gostariam de estar empregados no circuito superior, com melhor rendimento e acesso a direitos trabalhistas, como $13^{\circ}$ salário,

\footnotetext{
${ }^{3}$ A cidade local é entendida como o patamar mínimo de centro urbano, por ter suas funções conectadas ao "consumo mínimo", tendo-se em vista que oferece bens e serviços de uso básico e frequente os quais atendem demandas de uma população que, comumente, não tem condições de se deslocar para outras cidades cujo mercado é mais complexo.

${ }^{4}$ Definimos os centros regionais sertanejos do eixo rodoviário Natal-Caicó como importantes cidades do interior potiguar as quais, pela maior densidade de atividades econômicas e de serviços, inclusive do poder público (hospital regional, universidade, polo judiciário, instituições financeiras), atraem a população de centros locais, exercendo, assim, influência em dada dimensão regional.
} 
mas, como isso não é possível, por necessidade integram o circuito inferior. Nesse sentido, esse circuito mantém relação de complementaridade com o superior, abrigando aqueles que não são empregados ou que são desempregados nesse subsistema, assim mantendo a pobreza.

Além disso, há situações em que o circuito inferior é integrado por uma questão de oportunidade. Vários trabalhadores $(42,6 \%)$ disseram desenvolver atividade não hegemônica: para ajudar algum familiar (pai, mãe, esposo) e, desse modo, ter uma ocupação e algum rendimento; para complementar a renda familiar, já que desejam aumentar o rendimento que ganham no circuito superior; para melhorar a condição de vida da família; ou porque no circuito inferior ganham mais do que ganhavam no superior, além de poderem ficar mais tempo com os familiares. Assim sendo, de certo modo, o circuito superior concorre com o inferior pela maior precarização das relações de trabalho, já que há trabalhadores que asseveram que o subsistema superior é pior que o inferior, em termos de rendimentos obtidos e de intensidade de trabalho.

Também há agentes do circuito inferior do eixo rodoviário Natal-Caicó que são revendedores de grandes empresas ou marcas multinacionais (Natura, Avon) ou nacionais (La Paola Langerie, Polishop) dos ramos de cosméticos, perfumaria, vestimentas íntimas, produtos diversos para casa, para trabalho e pessoais, ou que exercem atividade especializada aprendida em curso superior, como, por exemplo, a elaboração de mapas. Outrossim, há situações em que funcionários públicos desenvolvem atividade no circuito inferior para complemento de renda familiar.

Como indicam os dados primários da pesquisa, a grande maioria das atividades desencadeadas no eixo Natal-Caicó são não hegemônicas, representando estratégias de obtenção ou aumento de renda pela maioria dos trabalhadores. Essas estratégias cada vez mais se complexificam na atualidade, havendo, inclusive, diferentes atividades exercidas no mesmo local de trabalho. Há várias situações em que duas atividades do circuito inferior são desenvolvidas conjuntamente, e também existem casos em que, numa atividade desse subsistema, é ofertado um serviço do circuito superior (figura 2). Com essa conjunção de atividades ou de tarefas, os agentes não hegemônicos objetivam aumentar sua freguesia, seus rendimentos e, dessa maneira, diminuir os riscos de falência de suas atividades. 


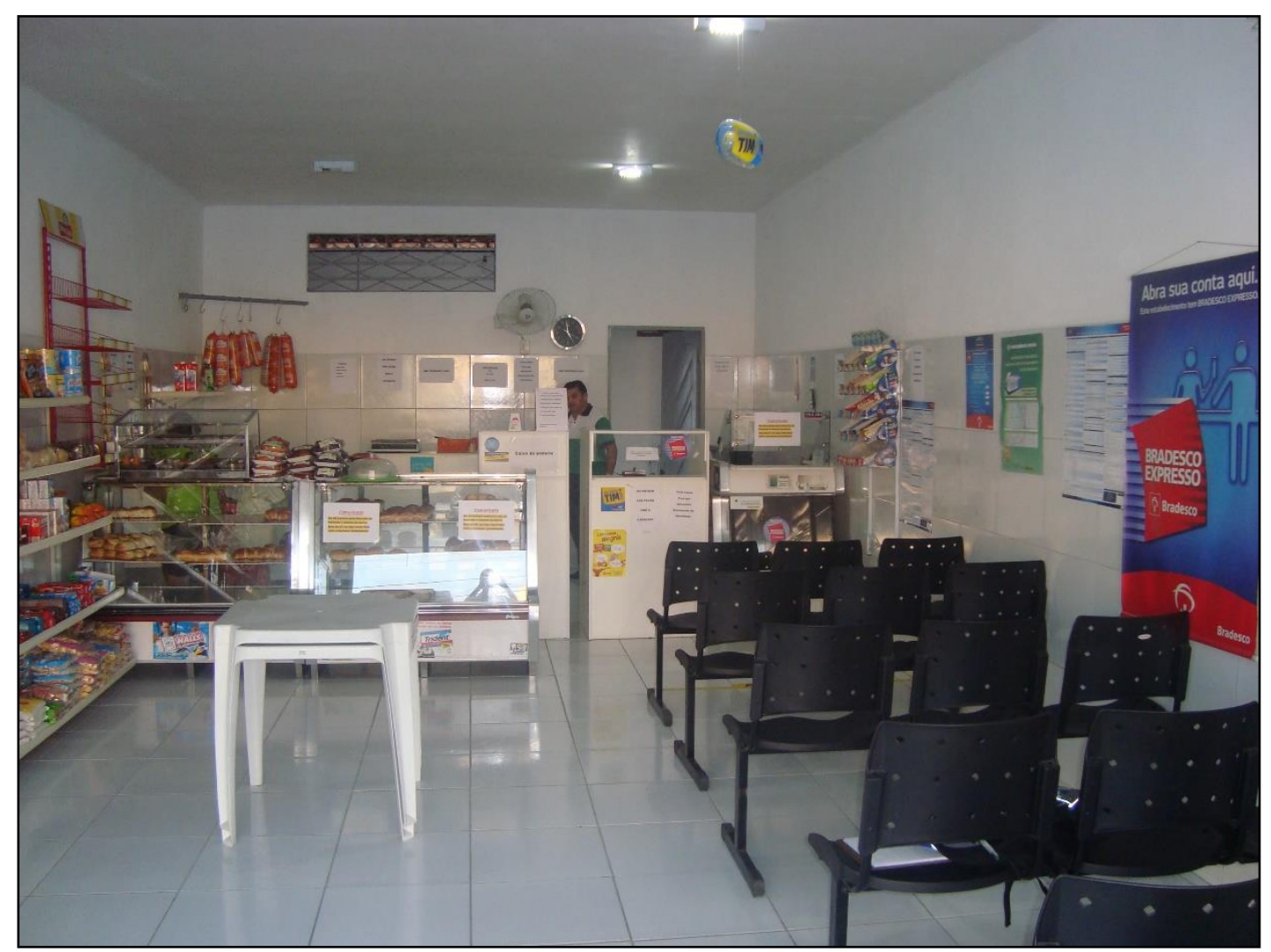

Figura 2 - Tangará - Atividade do circuito inferior (venda de pães, bolos, biscoitos, cereais) desenvolvida ao lado de atividade do circuito superior (correspondente bancário) Fonte: Fotografia do autor (2013).

Portanto, seja por uma questão de necessidade ou de oportunidade, assim como pelo desenvolvimento de uma ou mais atividades num só estabelecimento, o circuito inferior se apresenta como um resultado indireto da modernização econômica. Isso devido ao fato de as desigualdades de renda e as diferenças de acesso a bens e serviços serem a causa e o efeito da formação e da manutenção dos dois circuitos da economia urbana dos países subdesenvolvidos (SANTOS, 1978a). O circuito superior é uma consequência direta desse processo. O inferior, embora seja um efeito indireto e, até mesmo, indesejado da modernização, é importante para fazer perdurar a pobreza e para reproduzir de modo ampliado o capital.

Assim, a economia urbana subdesenvolvida é segmentada, mas não dual, já que os subsistemas que a caracterizam são decorrentes do mesmo processo, além de existirem em profunda conexão. 


\section{A DIFUSÃo dO CRÉdito FINANCEIRO ENTRE AGENTES DO CIRCUITO INFERIOR}

Enquanto a banalização das técnicas da informação e da comunicação ativa o mercado, a difusão do crédito financeiro estimula o consumo. Realiza-se, então, o casamento das variáveis técnica, informação, finanças e consumo, com sua difusão territorial e a alteração do funcionamento dos circuitos da economia urbana, em que se expande o mercado para o circuito superior juntamente com o crescimento da inserção de aspectos desse subsistema em atividades não hegemônicas (MONTENEGRO, 2006, 2011).

Ao contrário da produção, que elege seletivamente os subespaços para se instalar, as finanças se interessam pela totalidade do território usado, apresentando-se como uma variável determinante e dominante na atualidade da Globalização. Essa variável unifica diferentes capitais, pela drenagem sem limites da poupança popular para o circuito superior (SILVEIRA, 2004, 2007, 2009). Este, aproveitando-se da banalização da técnica, da informação e da capilaridade das finanças, expande-se social e territorialmente, não desprezando nenhum mercado (SANTOS, [1994] 2009).

Assim, Singer (2000) assevera que o crescimento econômico do Brasil, na atualidade, é comandado pelo capital financeiro, tendo como forte aliado o Estado nacional. Esse agente considera a financeirização da economia e do território como meio para a inclusão social, para a melhor qualidade de vida da população e para o fortalecimento do país no contexto mundial, colocando-se, dessa maneira, à disposição de porção de um nível hierárquico alto do circuito superior, constituída por bancos, fundos de pensão e de investimentos, consultorias e holdings integrados por empresas industriais, comerciais e de serviços avançados (SILVEIRA, 2009).

Nesse sentido, dados apontam para um vertiginoso crescimento do crédito financeiro no Brasil bem como remetem à amplificação da contratação desse crédito por atividades desenvolvidas por um só agente ou com a ajuda de familiares:

\footnotetext{
(...) o crédito [financeiro] representava 8,9\% do PIB [brasileiro] em 2005 e 15,8\% em 2010. (...) os instrumentos financeiros conheceram novos patamares, pois, os cartões de crédito triplicaram entre 2000 e 2009 e as vendas com cartões dobraram entre 2005 e 2009. Eram 40 milhões de brasileiros que tinham um cartão de crédito ou mais em 2000 , mas aumentaram para 128 milhões em 2009 (SILVEIRA, 2011, s.p.).
}

Outrossim, em 2008, as atividades do setor privado que mais tomaram empréstimo ao sistema financeiro foram aquelas desenvolvidas por uma pessoa física e/ou familiares. Entre 
1995 e 2002, esse tipo de empréstimo teve incremento real de $114 \%$ e, entre 2003 e 2008 , de 209\% (BRUGNOLA, 2009).

Assim, o circuito inferior não é excluído desse crescimento, mas, ao contrário, é hoje marcado por novas formas de pagamento oferecidas a seus clientes assim como por vinculações bancárias ou financeiras de seus agentes.

No que se refere às formas de pagamento ofertadas aos clientes, detectamos que o dinheiro continua sendo utilizado como principal forma de pagamento nos negócios realizados no circuito inferior do eixo rodoviário Natal-Caicó, devido à importância que a liquidez monetária tem para o desenvolvimento das atividades. Essa liquidez age como um lubrificante nas engrenagens do circuito inferior, pois proporciona saldar dívidas para a obtenção de novos créditos. Entretanto outras formas de pagamento são hoje possibilitadas, as quais evidenciam a complementaridade dos circuitos da economia urbana e a subordinação do circuito inferior ao superior.

Para os clientes mais antigos ou próximos, possibilita-se comprar fiado ou por meio de cheque pré-datado. Assim como é feito há muito tempo, registra-se o fiado em fichas ou em cadernetas, com anotação do nome do cliente, dos produtos comprados e da data em que houve a negociação. Nesses casos, vendedor e comprador acertam datas para o pagamento da dívida, as quais não prejudiquem nem o desenvolvimento da atividade econômica nem os rendimentos do cliente. Mas há também outras formas de registro do fiado: em notas promissórias, nas quais se discrimina a data da compra, a data para pagamento e os dados do cliente, que assina a promissória, confirmando os dados, ou em carnês, os quais são elaborados pelo próprio comerciante e utilizados para controle dos pagamentos efetuados.

Caso não haja o pagamento na data prevista, o agente do circuito inferior, munido do registro das compras, cobra ao cliente e busca receber o pagamento ou negociar outras datas. Em casos extremos, quando a cobrança não surte efeito, aciona-se o juizado de pequenas causas, para que seja feito um acordo. Para o juizado, geralmente, são levados os casos em que foram assinadas notas promissórias, as quais dão maior segurança na formulação de acordos formais. Desse modo, para os bons pagadores, o fiado é possibilitado com o registro em fichas, cadernetas ou mesmo com a elaboração de carnês ou a aceitação de cheques. Já para os clientes que podem não ser bons pagadores, apesar da proximidade com o agente desencadeador da atividade, exige-se a assinatura de notas promissórias, fato que evidencia certos limites nos contatos pessoais existentes no âmbito do circuito inferior do eixo rodoviário Natal-Caicó.

Além do dinheiro e do fiado, em suas diversas formas, há atividades do circuito inferior 
que vêm aceitando também cartão de crédito ou de débito como formas de pagamento. Para isso, o agente responsável procura um banco ou é procurado por uma instituição financeira ou empresa prestadora de serviços de cartões para ter em sua atividade uma ou mais maquinetas para aceitação de cartões, devendo, para isso, adequar-se às normas burocráticas e financeiras do banco, instituição ou empresa.

As instituições ou empresas que ofertam essas maquinetas para agentes do circuito inferior elencam as seguintes vantagens: mais opções de pagamento para os clientes, eliminação dos riscos com a inadimplência e possibilidade de aumento das vendas. Agentes que aderiram às maquinetas de cartão de crédito e débito em sua atividade destacam que, de fato, há clientes que preferem efetuar o pagamento com cartão e, por isso, tal forma de pagamento proporciona aumento nas vendas. Contudo reclamam das taxas cobradas pelo uso de linha telefônica para operar a maquineta, pelas vendas realizadas e pelo aluguel mensal da máquina, taxas, essas, que diminuem os rendimentos obtidos com o desenvolvimento de atividades não hegemônicas do eixo rodoviário Natal-Caicó.

Além disso, agentes que aderiram via operadora de cartão de crédito e débito ${ }^{5}$ afirmaram estar sofrendo com a inadimplência da empresa, que não repassa para eles os valores obtidos com as vendas com cartões. Esse fato coloca vários agentes em grave situação financeira, já que vendem e não recebem, o que os leva, muitas vezes, a deixar de aceitar o pagamento com cartão.

O crédito financeiro oferecido aos clientes do circuito inferior do eixo rodoviário NatalCaicó faz com que, por vezes, o fiado seja enfraquecido e o crédito aceito seja predominantemente o burocrático (figura 3). Do mesmo modo, limita a pechincha, a qual só é aceita nas compras à vista, já que nas compras com cartão de débito ou crédito há uma perda do lucro obtido, com o pagamento das taxas ao banco ou à instituição financeira detentora da

\footnotetext{
${ }^{5}$ A citada operadora é a Dap Brasil Soluções Empresariais LTDA. - PagTotal -, sediada em Aracaju, SE. A empresa tem um sítio na internet (<http://portaldorepresentante.com.br/empresas/8148-dap-brasil-solucoes-empresariais-ltdapagtotal-/>) que disponibiliza várias informações sobre sua atuação, seus produtos e as vantagens de adquiri-los ou utilizá-los. Ela adota a estratégia de não se associar diretamente a bancos, mas enviar representantes comerciais a micro e pequenas atividades econômicas para ofertar seus serviços financeiros aos responsáveis pelas atividades. Aqueles que se interessam por algum serviço da empresa devem preencher um contrato/cadastro com seus dados pessoais e bancários para incorporar em suas atividades o serviço financeiro contratado e receber os valores obtidos com vendas realizadas com cartões ou via sistema da operadora. Contudo também na internet há várias reclamações sobre a conduta dessa empresa (http://www.reclameaqui.com.br /4933225/pagtotal-dap-brasil/pagtotal/), por parte de pessoas que, assim como agentes do circuito inferior do eixo rodoviário Natal-Caicó, afirmam ter aderido a maquinetas de cartões em suas atividades, pela referida empresa, mas não ter recebido os valores correspondentes às vendas efetuadas. Além disso, há uma notícia sobre o encerramento das atividades da PagTotal, vinculado à forte concorrência enfrentada no mercado de pagamentos móveis no Brasil (http://cartaodecreditonocelular.com/pagtotal-encerra-atividades-de-pagamentosmoveis/).
} 
maquineta.

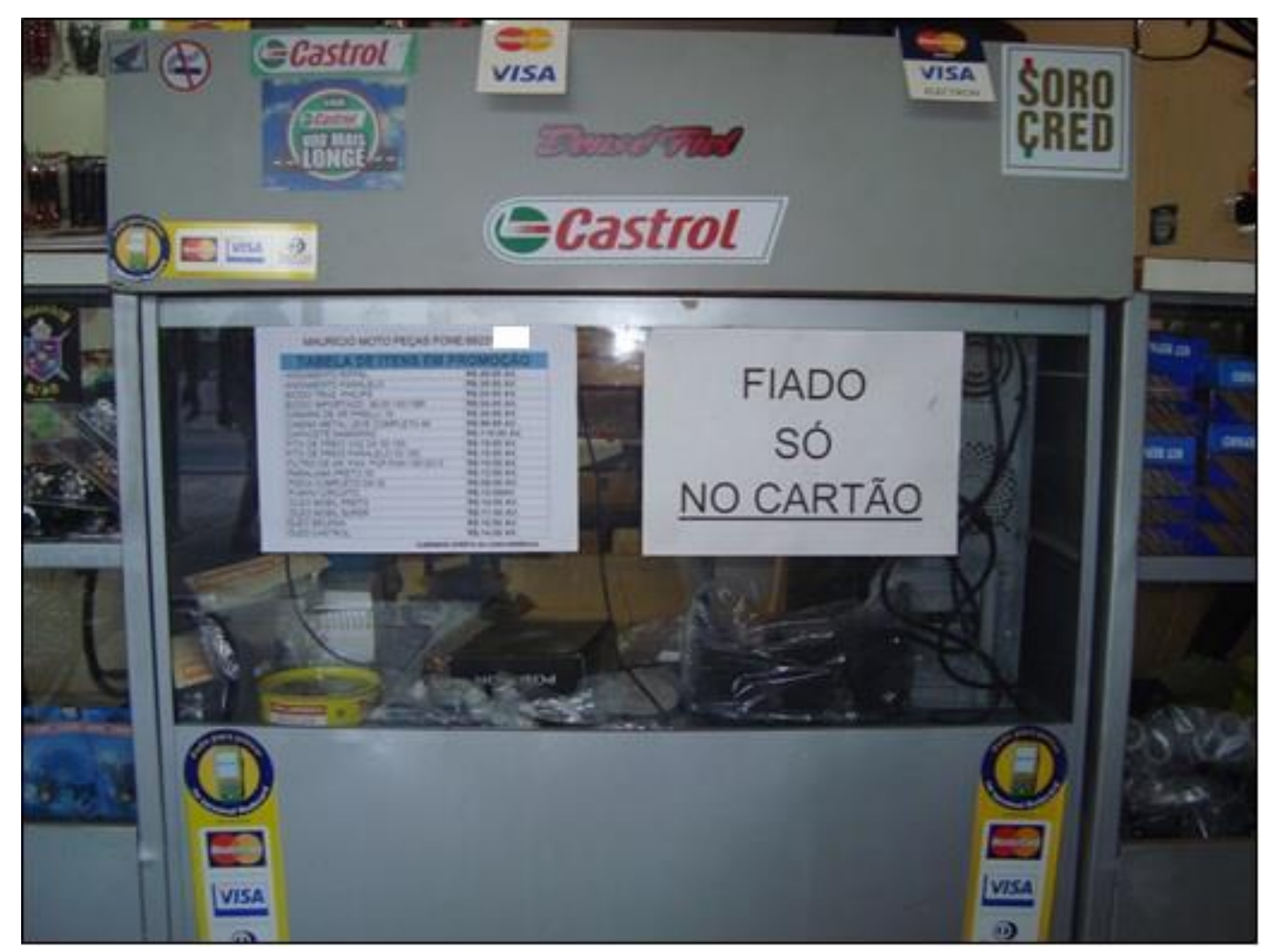

Figura 3 - Bom Jesus - Cartaz realçando o limite do fiado ao pagamento com cartão, fixado em atividade do circuito inferior Fonte: Fotografia do autor (2013).

A aceitação de cheque como forma do fiado, e de cartão de crédito ou de débito como formas de pagamento, no circuito inferior, decorre da complementaridade existente entre os circuitos. Os agentes desse circuito que aceitam cheque são, geralmente, aqueles que são vinculados a algum banco e que, portanto, depositam em sua conta os cheques de seus clientes. Para aceitar cartões em sua atividade, tais agentes devem possuir uma conta bancária e adequarse a normas do circuito superior. Sendo assim, esse circuito introduz, cada vez mais, normas burocráticas e instrumentos financeiros em atividades não hegemônicas, complexificando a organização destas e subordinando seus rendimentos, dos quais parte é drenada para atividades hegemônicas do ramo financeiro, com o pagamento automático de taxas diárias e mensais.

Já no que tange às vinculações bancárias ou financeiras de agentes do circuito inferior do eixo rodoviário Natal-Caicó, frisamos que a associação entre esses agentes e bancos é hoje uma realidade. Visando facilitar sua relação com fornecedores de mercadorias e/ou obter microcrédito para investir na atividade, ter capital de giro ou fazer uso pessoal, agentes desse subsistema utilizam serviços bancários, como conta corrente, conta poupança, cheque e cartão 
de crédito. Os bancos que mais vinculam tais agentes são Caixa Econômica Federal, Bradesco, Banco do Brasil e Banco do Nordeste, respectivamente.

Muitos $(43,2 \%)$ dos agentes do circuito inferior do eixo rodoviário Natal-Caicó que utilizam serviços bancários já realizaram empréstimo via programa de microcrédito. As finalidades mais recorrentes de seus empréstimos bancários são: investir na atividade, com a compra de mercadorias, de instrumentos ou de equipamentos de trabalho; reformar o estabelecimento em que a atividade é realizada, ou mesmo construir em terreno pertencente ao agente desencadeador da atividade ou a sua família. Há casos em que o dinheiro do empréstimo foi utilizado para comprar casa para residência, onde também é desempenhada a atividade do circuito inferior; para obter capital de giro para movimentar a atividade com menos insegurança, apesar da dívida contraída no banco; ou para uso pessoal, com a compra de bens modernos (carro, moto, computador) que também podem ser utilizados na atividade econômica desenvolvida.

Outrossim, frisamos que a associação de agentes do circuito inferior com bancos vem alterando a natureza do crédito nesse subsistema. Cada vez mais, eles deixam de tomar empréstimo a parentes, amigos e/ou agiotas, para fazerem isso em bancos, devido aos maiores valores oferecidos por essas instituições, à ausência do risco de se tornarem inadimplentes para com uma pessoa próxima, à existência de bancos que estão desburocratizando o crédito financeiro destinado a agentes da economia desenvolvida pelos pobres, como o Banco do Nordeste, com o Programa Crediamigo, e à de correspondentes bancários em todas as cidades do eixo rodoviário Natal-Caicó, localizados próximos dos agentes do circuito inferior, oferecendo-lhes atendimento particularizado, se necessário em horários flexíveis.

Os agentes do circuito inferior do eixo rodoviário Natal-Caicó que fazem empréstimo bancário para investir em sua atividade melhoram a estrutura do ambiente de trabalho (figura 4) e/ou expandem a variedade de mercadorias utilizadas ou comercializadas (figura 5). Assim, as atividades de tais agentes se destacam das dos que não requerem empréstimo, já que estes não têm condições de melhorar sua atividade. Entretanto, o endividamento dos agentes que tomam empréstimo compromete 30 a $40 \%$ da renda obtida e, muitas vezes, por falta de condições de pagamento da dívida, causa a falência da atividade e torna o proprietário inadimplente com o banco. Portanto, a complementaridade entre bancos e circuito inferior pode levar ao melhoramento estrutural e comercial de atividades desse circuito mas também à subordinação do rendimento obtido ao pagamento de taxas de juros altas para os níveis de capital dos agentes não hegemônicos, ocasionando falência e/ou inadimplência. 
Nesse sentido, fica explicitado que o endividamento bancário de agentes do circuito inferior pode ser importante, pois possibilita investimentos no desenvolvimento da atividade. Todavia, o endividamento, se não realizado para consumo imprescindível e dentro de limites condizentes com o nível de capital da atividade não hegemônica, pode ser somente uma forma de absorção da poupança popular pelo circuito superior, causando aumento da assimetria entre os circuitos da economia urbana.

Por isso, sugerimos mais reflexão sobre a concepção de que estratégias de elevar a oferta de empréstimos financeiros aos pobres devam ser imaginadas e implementadas. Dentre essas estratégias, Neri e Giovanini (2005) defendem a aceitação da casa própria ou de benefícios sociais recebidos pelos pobres como garantia de pagamento de empréstimos contratados. Contudo, há que se questionar: o caminho mais eficaz para o fortalecimento do trabalho e da vida dos agentes do circuito inferior é ofertar-lhes mais e maiores empréstimos? Esse caminho é, deveras, bom para quem: para os pobres ou para os bancos?

A realidade estudada contradiz a defesa dos autores, já que o endividamento de agentes do circuito inferior do eixo rodoviário Natal-Caicó pode colocá-los numa situação de angústia diária em busca de dinheiro para saldar dívidas. Por vezes, fazem-se mais dívidas para pagar outras já existentes, fato que pode levar à falência do negócio desenvolvido, com a intensificação da pobreza em que vivem os agentes do subsistema inferior e seus familiares.

\section{O ABASTECIMENTO DO CIRCUITO INFERIOR PELO CIRCUITO SUPERIOR}

Além do dinheiro líquido, do crédito pessoal direto e do crédito financeiro, o circuito inferior do eixo rodoviário Natal-Caicó é desenvolvido por meio de outro importante mecanismo financeiro: seus abastecedores de mercadorias, os quais lhe concedem crédito na forma de mercadorias e, por vezes, crédito burocrático, quando vinculados a alguma instituição financeira. Vale frisar que o crédito em mercadorias, geralmente, é condizente com o funcionamento da atividade abastecida, pois ocorre na forma de produtos demandados, sendo limitado, adiantado e com curto prazo para pagamento (SANTOS, 1978a).

O circuito inferior do eixo rodoviário Natal-Caicó é abastecido por atacadistas e/ou por transportadores, que estabelecem estreitas relações entre os circuitos da economia urbana. Os atacadistas são grandes empresas produtoras, ou empresas atacadistas que intermedeiam a produção superior e o varejo não hegemônico (XAVIER, 2009), enviando seus representantes comerciais às atividades do circuito inferior para que elas realizem os pedidos de mercadorias. Posteriormente, as mercadorias são entregues por outros funcionários da empresa. 
Revista de Geografia (Recife) V. 36, Nº. 2, 2019
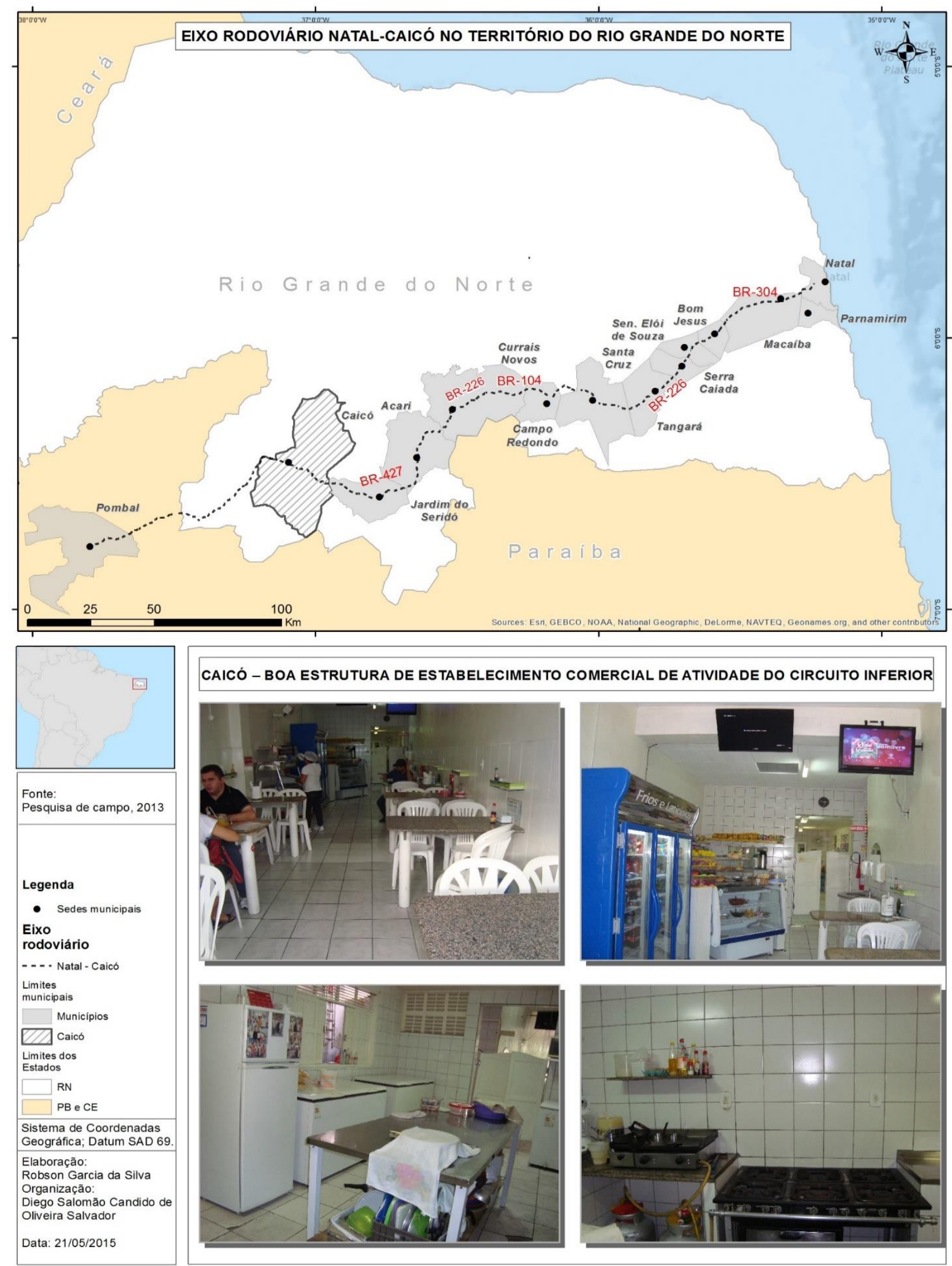

Figura 4 - Caicó - Boa estrutura de estabelecimento comercial de atividade do circuito inferior Fonte: Fotografias do autor (2013). 
Revista de Geografia (Recife) V. 36, Nº. 2, 2019
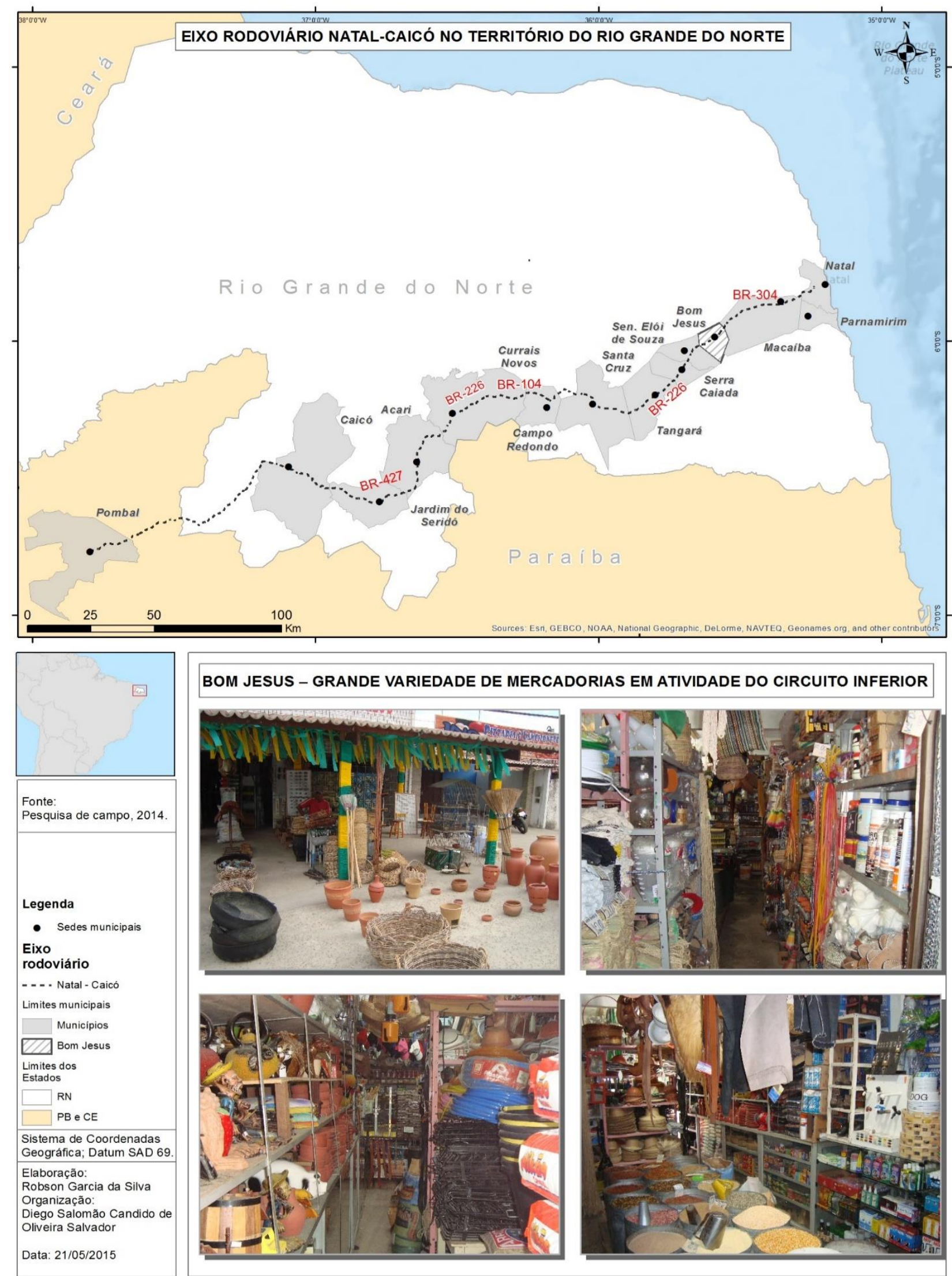

Figura 5 - Bom Jesus - Grande variedade de mercadorias em atividade do circuito inferior Fonte: Fotografias do autor (2014). 
Os transportadores são agentes do circuito inferior ou do circuito superior marginal que dispõem de carro, camionete ou caminhão e pequena quantidade de mercadoria adquirida no circuito superior ou com agricultores. Vendem para agentes do circuito inferior do eixo rodoviário Natal-Caicó e realizam a entrega no momento da compra, estabelecendo uma rede de mercadorias que evidencia a dinâmica entre os circuitos e a interna do circuito inferior.

Quanto mais pobre é o agente do circuito inferior, menores condições ele tem de se deslocar para outros espaços a fim de comprar mercadorias de que necessita e que não são comercializadas na cidade em que está, ou o são por preços elevados. Assim, ele é bastante dependente de atacadistas e transportadores para abastecer sua atividade.

Dessa maneira, no eixo rodoviário Natal-Caicó, a maioria $(60,8 \%)$ dos agentes do circuito inferior compra os produtos que utiliza ou comercializa em sua atividade de representantes de empresas de âmbito microrregional, estadual, macrorregional, nacional ou global. Geralmente, o pedido dos produtos é feito no local de trabalho dos agentes do circuito inferior ou por telefone, e as mercadorias são entregues posteriormente, por transportadoras ou pela própria empresa atacadista que as comercializou. Também há casos, referentes a transportadores de âmbito microrregional ou estadual, em que a entrega é feita concomitantemente à compra, semanal ou quinzenalmente.

Devido ao fato de a maioria das atividades do circuito inferior do eixo rodoviário NatalCaicó ser abastecida por atacadistas e/ou por transportadores, o agente desencadeador da atividade não hegemônica busca ter um estoque de mercadorias, que é armazenado, quando possível, no local da própria atividade ou na residência do proprietário, quando este mora próximo ou contíguo a seu trabalho.

Entretanto, diferentemente do atacadista e, em menor medida, do transportador, o agente do subsistema inferior do eixo rodoviário em questão não tem grande capacidade de estocar mercadorias, o que faz com que, em atividades desse circuito, o estoque seja pequeno e a rapidez da renovação dependa do nível de capital da atividade - quanto menor o nível, maior a rapidez da renovação -, assim como da frequência de entrega das mercadorias pelos atacadistas.

Sabedoras dessa situação, as empresas atacadistas, comumente, disponibilizam novos objetos técnicos (tablets conectados à internet, veículos modernos e ágeis) para seus representantes comerciais e treinam seus funcionários no sentido de otimizar o processo de distribuição de mercadorias. Assim, há rapidez na entrega das mercadorias solicitadas pelo circuito inferior em todo o território nacional, fato que adapta a logística do circuito superior às 
necessidades frequentes de mercadorias do subsistema inferior, tendo-se em vista a impossibilidade desse subsistema de dispor de grandes estoques (XAVIER, 2009).

Além da venda de mercadorias e do oferecimento de crédito, os representantes de atacadistas oferecem outros serviços aos agentes do circuito inferior do eixo rodoviário NatalCaicó, deixando de ser apenas abastecedores e passando a ofertar também serviços de suporte, de definição de estratégias e de qualificação. Tais serviços são estratégias das empresas hegemônicas para conquistarem mercados novos, estabelecendo vasos comunicantes diretos com o circuito inferior (SILVEIRA, 2007, XAVIER, 2009).

A ação dos fornecedores do circuito superior no circuito inferior evidencia, cada vez mais, intensa complementaridade entre os circuitos da economia urbana. Agentes daquele circuito ampliam suas vendas atendendo a demandas de agentes não hegemônicos, sugerindo, inclusive, os melhores produtos a serem utilizados ou vendidos no circuito inferior, fazendo sugestões sobre como as atividades desse subsistema devem ser geridas, incentivando uma burocratização dessas atividades, com a utilização de serviços contábeis e financeiros, e motivam também a divulgação do que é comercializado, caracterizando o espaço de trabalho do circuito inferior com pinturas, cartazes, banners, placas e instrumentos ou equipamentos de trabalho que identificam marcas conhecidas nacional ou globalmente.

Sendo assim, o circuito inferior do eixo rodoviário Natal-Caicó é abastecido comodamente por mercadorias conhecidas pelo grande público, tendo também a possibilidade de enfeitar o espaço de desenvolvimento com propaganda realizada pelo circuito superior. No entanto, essa relação de complementaridade faz com que os agentes do circuito inferior diminuam a própria produção de mercadorias e comprem mais e mais ao circuito superior assim como diminuam suas compras em outras atividades do circuito inferior, devido ao atendimento personalizado e às vantagens oferecidas pelos representantes comerciais do circuito superior. Assim, há uma ampliação do mercado para esse circuito e uma diminuição para aquele, fato que evidencia também certa subordinação da economia dos pobres à hegemônica, no que tange à rede de mercadorias.

Desse modo, Xavier (2009) afirma que o objetivo das empresas atacadistas, ao fornecerem serviços personalizados para agentes do circuito inferior, é modernizar sua atividade para que se torne mais competitiva, frente à concorrência de outras atividades, e, assim, cada vez mais, prescinda de abastecedores do circuito superior. Essa modernização deve ser calcada na transformação de aspectos não burocráticos do circuito inferior, como a proximidade no relacionamento com os clientes, significando burocratizar e formalizar a atividade não 
hegemônica ou, como dizem os representantes dos atacadistas, profissionalizá-la.

Contudo, mais do que competitivos, os abastecedores hegemônicos do circuito inferior anseiam que seus agentes se tornem subordinados aos interesses deles. Ou seja, as empresas atacadistas visam “(...) conquistar a fidelização dos clientes varejistas segundo um discurso que valoriza a confiança e a parceria” (XAVIER, 2009, p. 184).

Apesar desse desejo de abastecedores hegemônicos pela fidelização do circuito inferior, os agentes desse subsistema que dispõem de carro, camionete ou caminhão, ou que se reúnem para viajar juntos frequentemente se deslocam para outras cidades para comprar mercadorias mais baratas. Compra-se o máximo que é permitido pelo capital de que se dispõe e pela capacidade de estocagem. O objetivo é comercializar a preços mais baixos, atraindo clientes, diante da forte concorrência enfrentada.

No eixo rodoviário Natal-Caicó, grande parte $(51,3 \%)$ dos agentes do circuito inferior compra mercadorias também em outros municípios. Há situações em que agentes que não dispõem de veículo se unem a um amigo ou parente que tem carro e, dividindo os gastos com a viagem, se dirigem a outras cidades para comprar mercadorias. Além disso, por vezes, vários agentes do circuito inferior alugam ônibus para viagem de compras. Os centros urbanos mais procurados são, respectivamente, Natal; Fortaleza (CE); Caruaru, Santa Cruz do Capibaribe e Recife (PE); São Paulo (SP); Mossoró; e Campina Grande (PB).

Essa é a realidade da quase totalidade dos agentes do circuito inferior nas cidades locais do eixo rodoviário Natal-Caicó. Aqueles que desenvolvem sua atividade em cidades cujo mercado é mais complexo - capital estadual, cidades da Região Metropolitana de Natal, centros regionais sertanejos - também compram, comumente, mercadorias na própria cidade em que trabalham. A busca sempre é por novidades ou por produtos de certa qualidade que possam ser comercializados a preços acessíveis à maioria das pessoas.

Em decorrência de o circuito inferior ser abastecido por atacadistas, transportadores e/ou por meio de compras feitas pelo agente responsável em âmbitos externos, a escala de atuação desse subsistema, no que se refere à rede de mercadorias, é alterada na atualidade, não se limitando à cidade em que se localiza e à região, nem dependendo totalmente delas.

Hoje, o circuito inferior pode relacionar-se com circuitos espaciais de produção de escala nacional ou mesmo global, “(...) mesmo que tal integração envolva, em grande medida, apenas a etapa de distribuição junto ao consumidor final" (MONTENEGRO, 2011, p. 78). É evidente que o aumento da escala de atuação do circuito inferior decorre da amplificação das interdependências entre os circuitos da economia urbana e revela essa amplificação. 
Portanto, os circuitos da economia urbana tecem uma rede de mercadorias constituída por diferentes empresas, atividades e agentes, facilitando o consumo para todas as camadas sociais. A cidade é, nessa perspectiva, constituída como mercado complexo, ou melhor, como espaço banal, onde diferentes capitais podem reinar ou sobreviver.

Nessa complexidade urbana, o circuito superior, com a determinação das variáveis contemporâneas, do abastecimento do circuito inferior e da comunhão do Estado com seus interesses, macro-organiza o território e comanda a economia nacional, proporcionando a expansão do circuito inferior e a do consumo pelos pobres.

\section{CONSIDERAÇÕES FINAIS}

Não obstante o circuito inferior ser proeminente na economia urbana do eixo rodoviário Natal-Caicó, esse subsistema não existe separadamente; ele coexiste com o circuito superior, por relações de concorrência, complementaridade e subordinação.

Os circuitos da economia urbana concorrem no mercado do eixo rodoviário Natal-Caicó por mais clientes. O objetivo do circuito superior é amplificar sua lucratividade, enquanto ao circuito inferior, interessa principalmente maiores rendimentos, para melhores possibilidades de sobrevivência. Visando atingir esses escopos, diferentes estratégias são adotadas: os agentes hegemônicos comandam as variáveis-chave da contemporaneidade e, dessa maneira, macroorganizam a economia e o território; já os agentes não hegemônicos se aproveitam do uso de técnicas da informação para ofertarem novos serviços, querendo agradar a seus clientes e atrair novos.

Além disso, a concorrência entre os circuitos também é evidenciada pela precarização das relações de trabalho. Isso porque as condições de trabalho no circuito superior podem ser tão precárias quanto no circuito inferior, exigindo-se dos trabalhadores elevada intensidade de trabalho e pagando-se irrisórios ordenados. Sendo assim, há trabalhadores que integram a economia não hegemônica por oportunidade ou opção, tendo em vista que, já tendo trabalhado no circuito superior, destacam que o labor no subsistema inferior é "menos pior" do que naquele. No circuito inferior, o fato de o agente social poder ser seu próprio patrão parece compensar os baixos rendimentos obtidos e as longas jornadas de trabalho enfrentadas.

Todavia também há trabalhadores que desenvolvem atividades não hegemônicas por uma questão de necessidade, e não de opção. São aqueles que foram desempregados ou nunca estiveram empregados pelo circuito superior. Desse modo, o circuito inferior se complementa com o superior ao abrigar desempregados ou não empregados pelo subsistema comandante da 
economia urbana.

Do mesmo modo, mirando majorar sua freguesia, seus rendimentos e, assim, atenuar os riscos de falência de suas atividades, agentes não hegemônicos desenvolvem diferentes atividades no mesmo local de trabalho, havendo casos em que, numa atividade do circuito inferior, é oferecido um ou mais serviços do circuito superior, ocorrendo uma complementaridade plena entre os circuitos.

Tais complementaridades entre os circuitos da economia urbana trazem à tona, mais do que conexão entre os subsistemas, subordinação do circuito inferior ao circuito superior, já que, no atual processo de modernização econômica, tal complementaridade é concatenada com as determinações da economia hegemônica.

A introdução de instrumentos financeiros em atividades não hegemônicas e a vinculação bancária de seus agentes são aspectos que assinalam a dependência de um circuito em relação ao outro. Como formas de pagamento oferecidas aos clientes, agentes do subsistema inferior aceitam cheque e negociação com cartão de crédito ou de débito, aderindo, para isso, a normas de bancos ou de instituições de crédito burocrático como também à drenagem de parte dos seus rendimentos para esses agentes hegemônicos, via pagamento de taxas cobradas para o uso de técnicas comandadas pelo sistema financeiro.

A vinculação bancária de agentes do circuito inferior possibilita que estes façam empréstimos burocráticos visando melhorar a estrutura do seu ambiente de trabalho ou a diversidade de mercadorias ou serviços de seu negócio. Ao efetivar esse crédito tornam-se endividados e têm parte considerável de seus rendimentos comprometida pelo pagamento de altas taxas de juros. O baixo nível de capital das atividades desses agentes inviabiliza, por vezes, o pagamento do crédito contratado, tornando o trabalhador pobre inadimplente junto ao banco, o que pode ocasionar a falência de seu meio de sobrevivência.

$\mathrm{O}$ intrínseco relacionamento entre os circuitos da economia urbana, de acordo com as determinações do circuito superior, reestrutura as características do circuito inferior na atualidade. Ao formular a teoria do espaço dividido, Santos (1978a) definiu o subsistema inferior pelas atividades de pequena dimensão enraizadas no contexto local e interessantes para a população pobre. Hoje, com a incorporação de objetos técnicos modernos e de crédito financeiro na economia não hegemônica, a organização de atividades do circuito inferior é, de certo modo, burocratizada, aumentando a importância de capital para seu desenvolvimento e sua escala de atuação quanto à rede de mercadorias utilizadas ou comercializadas. Outrossim, nos dias atuais, o circuito inferior interessa tanto a pobres quanto a agentes do circuito superior, 
pois aqueles obtêm ocupação e renda e têm a possibilidade de consumir por meio dele, e estes o abastecem, ofertam crédito burocrático para seus agentes e enquadram suas atividades na formalização tributária.

Por fim, sublinhamos que a coexistência entre circuito superior e circuito inferior também parece se apresentar como fator estruturante do processo de urbanização do eixo rodoviário Natal-Caicó. Isso porque, a partir da década de 1970, as cidades desse território crescem veementemente, impulsionadas, sobretudo, pelo desenvolvimento de atividades econômicas predominantemente da economia não hegemônica, mas tendo como estrutura desse processo as relações entre diferentes intencionalidades, com a complementação subordinada do subsistema inferior ao superior. Assim, acreditamos que no eixo rodoviário Natal-Caicó há simetria entre os processos de modernização econômica, de intensificação da urbanização do território e de precarização das relações e do mercado de trabalho. Destarte, tal simetria será alvo de nossas reflexões e análises em um próximo artigo.

\section{REFERÊNCIAS}

BRUGNOLA, G. B. A expansão recente da oferta de crédito no Brasil: 2003-2008. 2009. Monografia (Bacharelado em Economia) - Universidade Estadual de Campinas, Campinas.

MONTENEGRO, M. R. O circuito inferior da economia urbana na cidade de São Paulo no período da globalização. 2006. Dissertação (Mestrado em Geografia Humana) - Universidade de São Paulo, São Paulo.

Globalização, trabalho e pobreza no Brasil metropolitano. O circuito inferior da economia urbana em São Paulo, Brasília, Fortaleza e Belém. 2011. Tese (Doutorado em Geografia Humana) - Universidade de São Paulo, São Paulo.

NERI, M. C. ; GIOVANINI, F. S. Negócios nanicos, garantias e acesso a crédito. Revista Economia Contemporânea, Rio de Janeiro, 9 (3), p. 643-669, set./dez. 2005.

SANTOS, M. O espaço dividido: os dois circuitos da economia urbana dos países subdesenvolvidos. Rio de Janeiro: Livraria Ed. Francisco Alves, 1978a.

. Pobreza urbana. São Paulo, Recife: Hucitec, UFPE, Comissão Nacional de Regiões Metropolitanas e Política Urbana, 1978 b.

. Por uma economia política da cidade: o caso de São Paulo. São Paulo: Editora da Universidade de São Paulo, [1994] 2009.

SENNETT, R. A cultura do novo capitalismo. Tradução de Clóvis Marques. Rio de Janeiro: Record, 2006. 
SILVEIRA, M. L. Globalización y circuitos de la economía urbana en ciudades brasileñas. Cuadernos del Cendes, ano 21, n. 57, tercera época, sep./dic. 2004.

. Crises e paradoxos da cidade contemporânea: os circuitos da economia urbana. In: X SIMPURB: TRAJETÓRIAS DA GEOGRAFIA URBANA NO BRASIL: TRADIÇÕES E PERSPECTIVAS, Anais... Florianópolis: UFSC, 2007.

Finanças, consumo e circuitos da economia urbana na cidade de São Paulo. Caderno CRH, Salvador, v. 22, n. 55, p. 65-76, jan./abr. 2009.

- Modernizações territoriais e circuitos da economia urbana no Brasil. In: XIV ENCONTRO NACIONAL DA ANPUR: QUEM PLANEJA O TERRITÓRIO? ATORES, ARENAS E ESTRATÉGIAS, Anais... Rio de Janeiro: UFRJ, 2011.

SINGER, P. O Brasil no limiar do terceiro milênio. Estudos Avançados, 14 (38), p. 247-259, 2000 .

XAVIER, M. A. M. Os elos entre os circuitos da economia urbana brasileira no atual período: os atacadistas distribuidores e seu papel intermediador. 2009. Tese (Doutorado em Geografia) - Universidade Estadual de Campinas, Campinas. 